\title{
Paraguay 2019: el comienzo inusual de Un gobierno SIN LUNA DE MIEL*
}

\author{
Paraguay 2019: The Unusual Beginning of a Government Without a \\ Honeymoon
}

\section{DIEGO ABENTE BRUN}

The George Washington University, Estados Unidos

\begin{abstract}
RESUMEN
El 2019 ha sido un año inusual para un gobierno que inicia su mandato, debido a la sucesión de crisis que llevaron al presidente Mario Abdo Benítez al borde de ser destituido vía juicio político. Este artículo analiza el periodo centrándose en tres dimensiones: la imbricación de la política exterior con la doméstica, o "intermesticidad", el convulsionado frente político, y la crisis económica. El artículo concluye que el 2020 será un año decisivo para determinar si el marcado deterioro de la suerte política del gobierno en su primer año será revertido y si la oposición podrá articular un frente opositor coherente y unido de cara al futuro. De cómo se resuelvan estas dos interrogantes depende en gran medida el escenario electoral de 2023 y cuáles serán las posibilidades de éxito del Partido Colorado y la oposición.
\end{abstract}

Palabras clave: Abdo Benítez, juicio político, Partido Colorado, intermesticidad.

\begin{abstract}
2019 has been an unusual year for a government that is beginning its term, due to the succession of crises that brought President Mario Abdo Benitez to the brink of impeachment. This article analyses the period by focusing on three dimensions: the overlapping of foreign and domestic policy, or "intermesticity", the convulsed political front, and the economic crisis. The article concludes that 2020 will be a decisive year for determining whether the marked deterioration of the government's political fortunes in its first year will be reversed and whether the opposition will be able to articulate a coherent and united opposition front for the future. How these two questions are resolved depends largely on the electoral scenario of 2023 and what the chances are for the success of the Colorado Party and the opposition.
\end{abstract}

Keywords: Abdo Benitez, impeachment, Colorado Party, intermesticity.

\footnotetext{
El autor agradece a los árbitros por su cuidadosa lectura del manuscrito original y sus valiosos comentarios y sugerencias, aunque no todos hayan podido ser recogidos debido a limitaciones de espacio. La responsabilidad del texto, por supuesto, es enteramente del autor. Agradece también a los editores su paciencia con los plazos en esta era de la Covid-19. Finalmente, lamenta no haber podido hacer justicia a la creciente producción bibliográfica de jóvenes cientistas sociales paraguayos solo algunos de los cuales han podido ser referenciados.
} 


\section{INTRODUCCION}

El 15 de agosto de 2018 asumió la presidencia de la República del Paraguay, Mario Abdo Benítez. Pocos presagiaban que para el año 2019 se convertiría en el primer año de gobierno más atípico de los últimos 30 años. Una encuesta realizada en agosto de 2019 por la encuestadora CIES para el diario Última Hora en agosto de 2019 en ocasión de cumplirse un año de gobierno arrojó conclusiones devastadoras: $69.3 \%$ de los encuestados reprobaba la gestión del presidente Abdo Benítez, justamente en el primer año que normalmente se caracteriza por otorgar al presidente entrante una alta aprobación (Última Hora 2019a).

Véanse los guarismos a continuación (Figura 1). En el caso de los gobiernos anteriores al de Horacio Cartes, los guarismos de Latinobarómetro fueron de $57 \%$ de aprobación para el presidente Nicanor Duarte Frutos (2003-2008) y 86\% para el gobierno de Fernando Lugo (2008-2012).

Figura 1. Calificación de la gestión del primer año del gobierno del presidente, comparando a Abdo Benítez con Cartes. Fuente: IBOPE-CIES
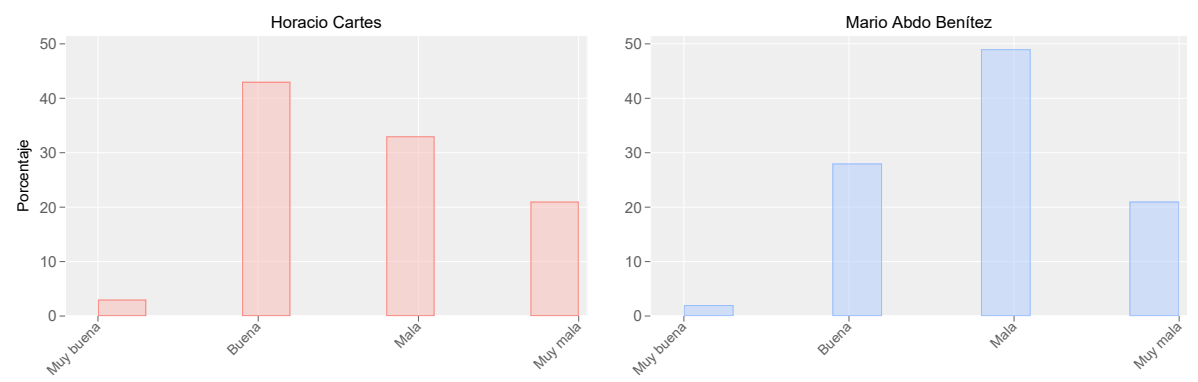

En realidad, para Mario Abdo Benítez fue un annus horribilis. La expresión Desastre ko Marito (Es un desastre Marito, en guaraní) se volvió viral. ¿Qué había sucedido? ¿Cómo explicar un resultado tan adverso en el año de la luna de miel $^{1}$ de un presidente? En el presente artículo se hará un análisis de este año centrado en los tres grandes ejes temáticos que dominaron la agenda nacional y fueron los que explican en gran medida esta situación.

En primer lugar, se analizará la dimensión de lo que, a los efectos de este estudio y forzando el castellano denomino intermesticidad. Como se conoce, el concepto "interméstico", ampliamente utilizado en el campo de las relaciones internacionales, fue acuñado en 1977 por el Presidente del Council of Foreign Relations de Estados Unidos, Bayless Manning, en un célebre artículo publicado

La expresión "luna de miel" ha sido tan utilizada que resulta imposible determinar quién la acuñó y la adaptó de las relaciones conyugales al análisis político y hasta deportivo y mucho menos cuál es su duración. La utilizo aquí por ende en un sentido laxo. 
en la revista Foreign Affairs (Manning 1977). Dicho concepto apuntaba al análisis de la intersección de la política doméstica con la exterior, y a la influencia de la primera sobre las segunda, y viceversa.

En ninguno de los gobiernos paraguayos desde 1993 se hubiese iniciado un artículo como este centrándose en esta variable. Este caso, sin embargo, es la excepción. Contrariamente a lo que sucede de ordinario en el primer año de gobierno, la variable de la política exterior fue la que alcanzó mayor preeminencia y sus resultados fueron tan francamente adversos que estuvieron a punto de provocar su destitución del presidente por la vía del juicio político.

En segundo lugar, se examinará el frente político, marcadamente influido por lo mencionado más arriba pero también resultado de factores y lógicas endógenas vinculadas al estilo de gobierno del presidente Abdo Benítez. En esta sección se explorará también el convulsionado escenario del Congreso, la reforma de la ley electoral y la división de la oposición.

En tercer lugar, el artículo abordará la crisis económica que se tradujo en que el año 2019 fuese el primer año de recesión desde 2003, con excepción del año 2009 severamente impactado por la crisis mundial del año anterior desatada por la quiebra de Lehman Brothers. En la conclusión se discutirán las perspectivas para el futuro.

\section{INTERMESTICIDAD}

En realidad, la primacía de lo interméstico se había iniciado en el año 2018 con una crisis con Israel (López 2019), producto de la decisión del gobierno de Abdo Benítez de revertir la decisión del gobierno anterior de trasladar la Embajada Paraguaya de Tel Aviv a Jerusalén y que marcó el inicio de la era de aguda intermesticidad que caracterizó el año 2019. Dos consecuencias de particular relevancia ameritan mencionarse. La primera, que el propio vicepresidente de Estados Unidos Mike Pence realice gestiones públicas para presionar al gobierno de Abdo Benítez a que revierta su decisión (Maza 2018). La segunda, que el presidente, aún antes del traspaso de mando, ejerciese el poder de "marcarle la cancha" al presidente entrante. ${ }^{2}$ El presidente Abdo Benítez reaccionó con cierta tibieza posiblemente sorprendido por la repercusión de su decisión, pero al mismo tiempo evidenciando una debilidad que le acompañaría durante todo el año (AP 2018). 


\section{La crisis del Acta Secreta}

La crisis mas grave del primer año de gobierno fue la llamada crisis del Acta Secreta y se relaciona con la renegociación del Anexo C del Tratado de Itaipú. Esta renegociación representa el desafío mas importante de la historia reciente del Paraguay. Revisar el Anexo de un tratado firmado entre dos dictaduras en 1973 sobre la construcción de la represa de Itaipú, la segunda mas grande del mundo, constituye el mas importante reto de política exterior de Paraguay desde la Guerra del Chaco, un desafío de proporciones mayúsculas.

El Anexo C del Tratado es el que establece las "Bases Financieras y de Prestación de Servicios de Electricidad de la Itaipú". Si bien es cierto que su alcance, en un sentido estricto, puede parecer limitado, su negociación es de extrema importancia y ofrece oportunidades para que el Paraguay obtenga reivindicaciones reclamadas por mucho tiempo, y a su vez puede abrir las puertas a que Paraguay renegocie también algunas cláusulas del Tratado altamente lesivas a sus intereses.

Entre las mismas figura no solo el precio de la energía en un sentido general, sino también el precio de venta de la energía garantizada, el de la energía excedente, el de la cesión del Paraguay al Brasil y el uso que el Paraguay pueda dar al 50\% que le corresponde.

Desde 1984, cuando la represa inició su funcionamiento, el precio recibido por Paraguay por su cesión de energía a Brasil fue muy inferior al de mercado, le privó de ingresos legítimos, y representó un subsidio para el Brasil. Solamente en el año 2012, luego del Acuerdo Lugo-Lula que triplicó los ingresos paraguayos, el país perdió al menos 750 millones de dólares (VCC 2013). Un estudio posterior de Miguel Carter estima la pérdida total durante 31 años en 54 billones de dólares (ABC Color 2018; Carter 2019). ${ }^{3}$

A ello se suma la denominada "deuda espuria", producto de la venta de energía a Brasil por debajo de los costos de producción entre 1997 y 2002, deuda contraída para que Brasil enfrente su crisis económica (VCC 2013). Estos datos explican por qué la renegociación del anexo C constituye para el Paraguay no solamente un tema técnico sino una "causa nacional" motivada por la necesidad de resarcir al menos en parte el perjuicio causado a sus intereses a lo largo de décadas.

Desde el inicio del mandato de Abdo Benítez, pero especialmente desde 2019, se constituyeron diferentes instancias de asesoramiento sobre la materia. El Partido Liberal Radical Auténico (PLRA), el Congreso, y diferentes organizaciones de la sociedad civil organizaron comisiones para el estudio del tema. La prensa publicaba numerosos artículos instando al gobierno a negociar con patriotismo y firmeza. 
El gobierno hablaba poco y no esclarecía cómo se abordarían las negociaciones ni quiénes participarían. Lo único que se sabía era lo que el presidente Abdo Benítez había manifestado en oportunidad de su reunión con el presidente Jair Bolsonaro en Itaipú, y es que él personalmente lideraría las negociaciones (La Nación 2019a).

En julio de 2019 se produjo la renuncia del Ing. Pedro Ferreira, presidente de la ANDE, la empresa estatal de electricidad, quien fue reemplazado por el Ing. Alcides Jiménez. La falta de claridad acerca de las razones de este cambio de altísima relevancia, especialmente en dicho contexto, levantó sospechas que fueron agravadas por el rol jugado por el Ing. Jiménez en la negociación del fuertemente cuestionado Acuerdo Cartes-Macri del 9 de agosto de 2018 para el otro gran emprendimiento binacional, Yacyretá.

Es en dicho contexto que el 24 de julio surge súbitamente a la luz pública el Acta Secreta del 24 de mayo que establecía las condiciones de operación de Itaipú hasta el 2023. Su difusión pública tuvo un impacto demoledor para el gobierno. El Ing. Ferreira declaró públicamente que su renuncia se debió a su negativa a firmar dicha acta, cuyo contenido entonces se hizo público. Presionado por un asesor del presidente Abdo Benítez que concurrió a su oficina con el texto para que lo firme, Ferreira le solicitó que le devuelva el acta al presidente, sin su firma, acompañada de su renuncia manuscrita que la redactó en dicho momento.

El acta contenía condiciones gravosas para el Paraguay que resultarían en un sobrecosto de entre 250 y 300 millones de dólares por la compra de electricidad por parte de la ANDE. Al mismo tiempo eliminaba un artículo, cuya inclusión había solicitado la ANDE, que le permitiría vender energía en el mercado brasilero a precio de mercado y no a precio de costo, como lo viene haciendo hasta el presente. La exclusión de dicha cláusula tendría que ver con un intricado procedimiento relacionado con la eventual privatización de Electrobras y que beneficiaría a la empresa brasilera LEROS, supuestamente vinculada con la familia Bolsonaro. La eliminación de dicha cláusula se hizo por la activa gestión del joven abogado de 27 años José Rodríguez, relacionado con vicepresidente Hugo Velázquez, quien por razones desconocidas participó activamente en las negociaciones (Última Hora 2019b). ${ }^{4}$

Gradualmente fueron conociéndose los detalles que rodearon la suscripción de la fallida acta secreta. Sus negociadores habían sido el Embajador paraguayo en Brasil, Hugo Saguier Caballero, y el Ing. Alcides Jiménez. El ministro de Relaciones Exteriores Luis Castiglioni dijo desconocer sus términos ya que había sido negociado por el embajador Saguier Caballero y terminó renunciando, junto a Saguier Caballero, Jiménez y el director paraguayo de Itaipú, José Alberto Alderete (Agencia EFE 2019). El presidente Abdo Benítez dijo que se

En el caso paraguayo, conocedores de la materia señalan que la presencia de personas ajenas a las instituciones involucradas en un proceso o licitación de magnitud es un indicio de la participación de un padrino político al cual representarían. 
había familiarizado de los detalles a través de la prensa y que pediría a sus funcionarios una explicación detallada. Sin embargo, la difusión de mensajes de WhatsApp hecho público por el Ing. Ferreira demuestran lo contrario. Indicaban también que había habido una fuerte presión del gobierno brasilero para su aprobación (ABC Color 2019a).

La crisis se profundizó y aceleró y para fines de mayo llevó a la decisión de iniciar un juicio político al presidente Abdo Benítez por la causal de "traición a la patria". A la tarde del 31 de julio se confirmó que la bancada del sector cartista en la Cámara de Diputados decidió apoyar el enjuiciamiento, con lo cual se contaba con la mayoría de dos tercios absolutos, 53 de 80 diputados, requerida por la Constitución para el efecto. El 1 de agosto Paraguay y Brasil firmaron un documento que anulaba el acta. En una frenética noche de negociaciones Abdo Benítez logró un acuerdo con Horacio Cartes para desactivar el juicio y el 2 agosto ya podía respirar tranquilo. "Tengo en mi poder el Acta Bilateral que anula totalmente el último tratado, firmado el 24 de mayo pasado; con esto creemos que se repara totalmente el daño. Celebramos esta gran victoria de la ciudadanía y con esto, también ya nos retiramos de la intención de llevar adelante el juicio político al presidente y al vicepresidente", indicó el diputado Pedro Aliana, presidente del Partido Colorado y diputado leal a Cartes (Cálcena Ramírez 2019).

Varios elementos influyeron en el logro de dicho resultado. En primer lugar, Bolsonaro dio su respaldo a Abdo Benítez y aseguró que Brasil anulaba el acta y estaba dispuesto a renegociarla. Estados Unidos también los apoyó públicamente a través de sendos tuits de su embajador en Paraguay Lee McLeeny (Última Hora 2019c). Por otro lado, conocedores del caso aseguran que intervino también el primer ministro israelí, Benjamin Netanyahu, quién, a pedido de Estados Unidos, habría intermediado con Cartes. Para la madrugada del día siguiente Abdo Benítez había evitado su destitución y salvado su gobierno y expresó: "Pido disculpas, si es que me equivoqué". ${ }^{5}$ No fue una sorpresa por lo tanto que una encuesta de CIES para el diario Última Hora indicara que el $63 \%$ de los encuestados consideraran que el presidente no estaba preparado para renegociar y que, para el efecto, solo el 20\% confiaba en el presidente (Última Hora 2019d).

De haberse producido la destitución del presidente y el vicepresidente, es decir de doble acefalía, le seguía en la línea de sucesión el presidente del Congreso, Senador Blas Llano, líder del sector liberal aliado con el cartismo desde el período anterior. De conformidad con la Constitución le correspondería completar el mandato del presidente destituido, cuatro de los cinco años del periodo, sin haber sido electo para el cargo, aunque debería convocarse a la elección de un nuevo vicepresidente. Este evidente error de la Constitución que lleva a que la vacancia del presidente no requiera elección de un sucesor pero si lo exija la vacancia del vicepresidente esta sin embargo explícitamente establecido y hubiese llevado a un reprise de la situación de doble acefalía de 1999, cuando el presidente del Congreso Luis González Macchi completó mas de cuatro de los 
cinco años del mandato de su predecesor, Raúl Cubas Grau, aun teniendo un Vice-Presidente, Julio César Franco, que sí había sido electo para reemplazar al asesinado Vice-Presidente Luis María Argaña.

Muchos cabos quedan por atar en el análisis de la crisis. ¿Hubo quizás un compromiso de que Llano renunciase a favor de un eventual vicepresidente electo? ¿Qué concesiones extrajo Horacio Cartes del presidente Abdo Benítez? En el caso de Israel parecería obvio pues el gobierno decidió declarar organizaciones terroristas a Hamas y Hezbollah (AFP 2019).

Un ganador indudable de la crisis fue Horacio Cartes, quien exhibió su fuerza para sostener o derrumbar al gobierno. Sin embargo, no debe perderse de vista que eso solo fue posible porque la oposición asumió la misma postura. Cartes solo con sus votos en ambas Cámaras no puede alcanzar sus fines. Aún así, pretendió proyectar la imagen del King-maker o su reverso, el King-breaker como estrategia para potenciar su poder en el imaginario político.

\section{La no-crisis: relación con Estados Unidos}

A lo largo del 2019 el gobierno intentó mejorar su posición fortaleciendo su relación con Estados Unidos, lo que sería una demostración del éxito de su gobierno en el exterior a pesar del poco reconocimiento interno. En el transcurrir de un solo año se produjeron tres hechos importantes.

El primero fue la visita de Ivanka Trump (Última Hora. 2019e). El segundo, la visita del Secretario de Estado Mike Pompeo, primera de un Secretario de Estado al Paraguay desde la visita de Dean Rusk en abril de 1965. La visita de Rusk se había realizado justo en el contexto de la crisis producida por la invasión brasilera de territorio paraguayo en Puerto Renato en los Saltos del Guairá, cuyo potencial hidroeléctrico se utilizaría mas tarde para la construcción de la represa de Itaipú. Las fuerzas brasileras se retiraron del territorio paraguayo al día siguiente (ABC Color 2019b). Finalmente, el "broche de oro" para el gobierno de Abdo Benítez fue la reunión con el presidente Trump a fines del año, el tercer espaldarazo a su gobierno (White House 2019).

\section{La crisis del caso Arrom-Martí}

Otro de los frentes fue el caso Arrom-Martí. Juan Arrom y Anuncio Martí fueron acusados de liderar el secuestro de Edith Bordón de Debernardi a fines de 2001. En enero de 2002, después de estar aparentemente desaparecidos por dos semanas fueron ubicados en un operativo periodístico y lograron salir de la casa en la que se encontraban. Exhibían evidentes rasgos de haber sido a sometidos a torturas, o al menos a considerable violencia física. ${ }^{6}$ 
Aunque no sea posible establecer con certeza lo que realmente sucedió, observadores imparciales estiman que en realidad se trató de un doble secuestro. Por una parte, Arrom y Martí habrían liderado el secuestro de la Sra. Bordón de Debernardi. Por la otra, y habiéndose descubierto el caso y ubicado a sus presuntos autores, un grupo policial los secuestró a fin de apoderarse de parte del botín. Una aparente desavenencia en la repartición de éste habría a su vez llevado a que se filtre la información de dónde se encontraban (Última Hora 2019f).

Iniciado el proceso judicial en su contra por el caso del secuestro, los mismos huyeron al Brasil donde obtuvieron estatus de refugiados. Desde allí iniciaron una demanda al Estado paraguayo ante la Comisión Interamericana de Derechos Humanos. La Comisión remitió las observaciones de los demandantes al gobierno paraguayo el 30 de junio de 2017 y como hasta el 15 de agosto de 2018 el gobierno paraguayo no había presentado su respuesta, remitió el caso a la Corte Interamericana de Derechos Humanos.

Arrom y Martí reclamaban una indemnización de 123 millones de dólares, suma que obviamente no guardaba proporción alguna con la presunta violación de sus Derechos Humanos. La Corte fijó la fecha de 3 de junio para emitir su sentencia. El gobierno realizó una fuerte campaña mediática al punto que el propio presidente acudió a la lectura del fallo. La Corte falló a favor del gobierno paraguayo y el gobierno lo celebró como un ejemplo mas de su exitosa gestión (ABC Color 2019c).

La victoria sería breve, sin embargo, y pronto se convertiría en una nueva derrota. El gobierno logró que el Brasil revocará el estatus de refugiados a Arrom y Martí, pero al momento de dictarse la medida ambos ya habían buscado protección en Uruguay. El gobierno de Abdo Benítez inició las gestiones de extradición contando con la asesoría de un abogado uruguayo que aparentemente atendió el caso con negligencia. La acción del gobierno resultó un fiasco porque antes de que la jueza se expidiera, Arrom y Martí se encontraban en un vuelo con dirección a Finlandia, que les había otorgado estatus de refugiados (Última Hora 2019g).

Las instancias de política exterior discutidas aquí fueron marcadamente intermésticas y generaron profundas repercusiones domésticas. La crisis del Acta Secreta del 24 de mayo estuvo a un paso de llevar a la destitución del presidente. La relación con el gobierno Trump tuvo una connotación menor, pero también agitó las aguas que dividen a los sectores de derecha de los progresistas. De la misma manera, la crisis del caso Arrom-Martí reavivó la polémica ideológica. Los sectores progresistas condenaron que el Estado pretendiese eludir su responsabilidad en su secuestro, sin por ello defender a Arrom y Martí en el caso del secuestro. 


\section{EL FRENTE POLITICO}

\section{Un gobierno débil}

Las recurrentes crisis analizadas en la sección anterior tuvieron su correlato en el nivel de inestabilidad doméstica. En parte puede considerarse que la debilidad del primer gabinete de Abdo Benítez fue también parcialmente responsable de la intensidad y alcance de las crisis. Como señalan Milda Rivarola y Marcos Pérez Talia, el presidente, falto de liderazgo, se rodeó de asesores de poco peso (Última Hora 2019h). La encuesta de CIES citada al inicio de este artículo indica que más del $83 \%$ de los entrevistados consideraban que el presidente debía cambiar su gabinete y solo el 16\% lo consideraba bueno.

El gabinete del primer año de gobierno contó solo con cuatro figuras políticas sólidas y de proyección nacional. La primera fue el canciller Luis Castiglioni, exvicepresidente, cuya gestión a cargo del Ministerio fue primero gris y luego, con el escándalo del Acta Secreta, catastrófica.

José Alberto Alderete, quien fuera mano derecha del expresidente Nicanor Duarte Frutos, ocupó el cargo de director de Itaipú. Esta importante posición le permitió influenciar el manejo de su billonario presupuesto y ejercer la representación de los intereses nacionales en la empresa binacional. Como se ha visto más arriba, esta fue precisamente la razón que antes de completar el año haya sido obligado a renunciar.

Un actor de mucha experiencia fue Juan Ernesto Villamayor a quien le fue encomendado el Ministerio del Interior cuando que muchos pensaban que sería jefe del Gabinete Civil. Desde el Ministerio del Interior desgastó su figura y cargó con la crítica pública por la persistente inseguridad ciudadana y corrupción en filas de la Policía Nacional.

La cuarta figura importante, pero de menor envergadura política, fue su Ministro de Obras Públicas y Comunicaciones, Arnoldo Wiens. Con buena imagen en la opinión pública, Wiens fue también blanco de mucha crítica por la lentitud con la que ejecutó el presupuesto de su cartera, la que quizás más impacto tiene sobre la economía, pero también una en la que se han dado los mayores escándalos de corrupción.

Sin embargo, ninguna de estas figuras, ni individualmente ni en conjunto, logró despejar la imagen de debilidad que el gobierno proyectó desde el primer momento, quizás desde la humillación a la que le sometió Cartes en el caso de la relación con Israel cuando le obligó a ceder a la presión del expresidente y de la extrema derecha evangélica (López 2019).

La relación del Ejecutivo con el Congreso no fue fácil. Al inicio de su mandato, el presidente logró que dos congresistas afines presidieran ambas cámaras. En 
la Cámara de Diputados fue electo presidente Miguel Cuevas, ex cartista, con el apoyo de la oposición. Su rival, apoyado por el cartismo y el llanismo, ${ }^{7}$ fue el diputado Pastor Vera Bejarano. En la Cámara de Senadores fue electo Silvio Ovelar, en este caso apoyado por los oficialistas, el llanismo y el cartismo.

Sin embargo, ni una presidencia ni la otra lograron asegurar que el gobierno hiciera aprobar su agenda legislativa, o frenase la de sectores opositores del Congreso. En la tabla 1 se puede ver la evidencia de ello a través del análisis de la suerte corrida por los vetos presidenciales.

Los vetos - $\mathrm{u}$ objeciones como los denomina la constitución paraguaya - representan la expresión más ostensible del poder del Ejecutivo vis-á-vis el Congreso. En la normativa paraguaya - es cierto - el umbral de rechazo es bajo. Con una mayoría absoluta, es decir la mitad más uno de los miembros del cuerpo, el Congreso puede rechazar el mismo, aunque es preciso que ambas cámaras se pronuncien en el mismo sentido pues en caso contrario prevalece el Ejecutivo. Las diferencias generalmente no responden a la posición de las Cámaras con relación al Ejecutivo sino a que ambas discreparon en el texto de la ley y que por el procedimiento legislativo establecido en la constitución la cámara de origen perdió la pulseada con la cámara revisora. La aceptación del veto pues no es necesariamente un triunfo del Poder Ejecutivo.

Tabla 1. Resultado de los vetos presidenciales

\begin{tabular}{|c|c|c|c|}
\hline Leyes vetadas & $\begin{array}{l}\text { Veto aceptado por } \\
\text { una Cámara }\end{array}$ & $\begin{array}{l}\text { Veto aceptado } \\
\text { ambas Cámaras }\end{array}$ & $\begin{array}{c}\text { Vetos } \\
\text { rechazados }\end{array}$ \\
\hline $\begin{array}{l}\text { Ley } \mathbf{n}^{\circ} 6.302 \text { del régimen de } \\
\text { jubilaciones para profesionales } \\
\text { médicos }\end{array}$ & & & Rechazado \\
\hline $\begin{array}{l}\text { Ley } n^{0} 6.325 \text { que declara de interés } \\
\text { social y expropia }\end{array}$ & $\begin{array}{l}\text { Diputados: Rechazo } \\
\text { Senado: Aceptación }\end{array}$ & & \\
\hline $\begin{array}{l}\text { Ley } \mathrm{n}^{\circ} 6.333 \text { que "que organiza la } \\
\text { corte suprema de justicia". }\end{array}$ & $\begin{array}{l}\text { Diputados: Rechazo } \\
\text { Senado: Aceptación }\end{array}$ & & \\
\hline \multicolumn{4}{|l|}{ Ley $\mathrm{n}^{\circ} 6.337$ jubilacion } \\
\hline \multicolumn{4}{|l|}{ Odontólogos/bioquímicos } \\
\hline $\begin{array}{l}\text { Ley } \mathrm{n}^{\circ} 6.340 \text { de la pérdida de la } \\
\text { investidura parlamentaria. }\end{array}$ & $\begin{array}{l}\text { Diputados: rechazo } \\
\text { Senado: aceptación }\end{array}$ & & \\
\hline $\begin{array}{l}\text { Ley } n^{\circ} 6.348 \text { que declara zonas de } \\
\text { protección }\end{array}$ & & Aceptado & \\
\hline $\begin{array}{l}\text { Ley } n^{\circ} 6.349 \text { "que establece el } \\
\text { programa "ñane energía" }\end{array}$ & & Aceptado & \\
\hline $\begin{array}{l}\text { Ley } n^{\circ} 6.356 \text { que declara de interés } \\
\text { social y expropia }\end{array}$ & & Aceptado & \\
\hline
\end{tabular}




\begin{tabular}{|c|c|c|c|}
\hline Leyes vetadas & $\begin{array}{l}\text { Veto aceptado por } \\
\text { una Cámara }\end{array}$ & $\begin{array}{l}\text { Veto aceptado } \\
\text { ambas Cámaras }\end{array}$ & $\begin{array}{c}\text { Vetos } \\
\text { rechazados }\end{array}$ \\
\hline $\begin{array}{l}\text { Ley } n^{\circ} 6.364 \text { "que declara de interés } \\
\text { social y expropia }\end{array}$ & & Aceptado & \\
\hline $\begin{array}{l}\text { Ley n }{ }^{\circ} 6.367 \text { ley n }{ }^{\circ} 5016 / 14 \\
\text { "nacional de tránsito y seguridad } \\
\text { vial". }\end{array}$ & & Aceptado & \\
\hline $\begin{array}{l}\text { Ley } \mathrm{n}^{\circ} 6.376 \text { que amplía el } \\
\text { presupuesto general }\end{array}$ & & & Rechazado \\
\hline $\begin{array}{l}\text { Ley } \mathbf{n}^{\circ} 6.381 \text { que modifica y amplía } \\
\text { la ley n } \mathrm{n}^{\circ} 3728 / 09 \text { "que establece el } \\
\text { derecho a la pensión alimentaria } \\
\text { para las personas adultas mayores } \\
\text { en situación de pobreza". }\end{array}$ & & & Rechazado \\
\hline $\begin{array}{l}\text { Ley } n^{\circ} 6.390 \text { que regula la emisión } \\
\text { de ruidos. }\end{array}$ & & & Rechazado \\
\hline $\begin{array}{l}\text { Ley } n^{\circ} 6.403 \text { que regula la } \\
\text { inmovilización de activos } \\
\text { financieros de personas relacionadas } \\
\text { con el terrorismo }\end{array}$ & & Aceptado & \\
\hline $\begin{array}{l}\text { Ley } n^{\circ} \mathbf{6 . 4 2 6} \text { que modifica el } \\
\text { presupuesto general de la nación } \\
\text { para el ejercicio fiscal } 2019\end{array}$ & $\begin{array}{l}\text { Diputados: Rechazo } \\
\text { Senado: Aceptación }\end{array}$ & & \\
\hline TOTAL: 15 & 4 & 6 & 5 \\
\hline
\end{tabular}

Del análisis de la tabla 1 pueden inferirse ciertas conclusiones. $60 \%$ de los vetos fueron rechazados o aceptados por disidencias entre las Cámaras. Todos los proyectos importantes vetados por el Ejecutivo fueron rechazados. Dichos proyectos versaban sobre jubilaciones, pensiones para adultos mayores en situación de pobreza y presupuesto. Los vetos aceptados fueron de leyes de relativa poca importancia, salvo la Ley Nane Energía que planteaba que los gastos "sociales" de Itaipú y Yacyretá fueran utilizados para disminuir la tarifa de la electricidad. Si bien la Ley fue aprobada, era de público conocimiento que la mayoría del Partido Colorado iba a aceptar el veto pues dichos fondos son un importante capital para el proselitismo político y el clientelismo y son de utilización totalmente discrecional. Los vetos aprobados en disidencia tuvieron siempre a la Cámara de Senadores votando por la aprobación y se relacionaron con casos de expropiación por razones de interés social vinculados con los departamentos en los que los diputados son electos. En dicha Cámara, en un tácito quid pro quo dichos proyectos son aprobados por ambos partidos tradicionales.

\section{La oportunidad perdida}

Después de la crisis del Acta Secreta se esperaba que el presidente realizara cambios profundos en su gobierno y lo "reinventara". Sin embargo, los mismos no se produjeron hasta que sendos escándalos forzaron a Abdo Benítez a 
realizarlos. Una vez más el presidente reaccionaba a situaciones de crisis luego de no haber exhibido liderazgo y control de la agenda política (Última Hora 2019i).

La primera situación dio por terminada la carrera de su Jefe de Gabinete, Julio Ullón, quien ya había sido vinculado con la empresa LEROS en el caso del Acta Secreta. En esta oportunidad desató un revuelo político y expuso al presidente a severas críticas. Ullón fue quien orquestó la visita del empresario mexicano Juan Fernández, supuesto representante de Lamborghini y el anuncio de que la misma establecería una fábrica en Paraguay. Este anuncio fue ampliamente difundido, incluso en la cuenta del Twitter del presidente. Al comprobarse que tal hecho no tenía sustento alguno y que ni siquiera Fernández era representante de Lamborghini, Ullón no tuvo más alternativa que renunciar (Última Hora 2019j).

En octubre de 2019 se produjo el primer cambio de gabinete. Poco tiempo antes se había producido la espectacular fuga de un conocido y peligroso criminal. Jorge Teófilo Samudio, alias Samura, se fugó mientras era trasladado a un juzgado para declarar y dio muerte al comisario Félix Ferrari, quien conducía la caravana policial. Ello derivó en la renuncia del ministro de Justicia, Julio Rivas y del comandante de la Policía. Pero también provocó la renuncia del ministro Villamayor (Última Hora. 2019k).

El reemplazante de Villamayor fue Euclides Acevedo, un conocido dirigente político miembro del Partido Febrerista y del Encuentro Nacional. Acevedo, que al momento de su designación no se encontraba realizando militancia partidaria activa, había sido también una importante figura en la lucha contra la dictadura stronista. Aunque había ocupado cargos de Diputado y embajador en España, era sin embargo más conocido por su experticia en asuntos de seguridad. Se trataba, sin duda, de un dirigente de gran peso político y que no provenía del Partido Colorado. El cargo de ministro del Interior parecía hecho a su medida y su incorporación al gabinete fue sin duda un refuerzo importante para el gobierno.

\section{Un Congreso convulsionado}

En el Senado, las aguas también se enturbiaron. Dos casos de corrupción llevaron a que el mismo decretara la pérdida de investidura de dos de sus miembros: el Senador colorado Víctor Bogado (Lovera 2019) y el liberal Dionisio Amarilla. El Senador Bogado venía soportando una antigua acusación de malversación de fondos públicos, que a través de múltiples recursos procedimentales había logrado frenar. Como en otros casos de corrupción, el objetivo de los imputados es extender el proceso al máximo, utilizando las llamadas "chicanas" judiciales hasta que el caso quede extinto por cumplimiento del plazo disponible para dictar sentencia. Por otra parte, el Senador Amarilla había sido grabado y filmado en un episodio de evidente tráfico de influencia (Última Hora. 2019l). 
En ambos casos la presión de la opinión pública y la crítica de la prensa lograron que se obtenga la mayoría necesaria para que ambos sean expulsados del cuerpo y reemplazados por sus suplentes. ${ }^{8}$

Igual suerte, pero por otro motivo, sufrió el senador Paraguayo Cubas (ABC Color 2019d). Cubas, un mediático legislador, se caracterizó por protagonizar y filmar en su cuenta de Facebook polémicas acciones que incluían enfrentamientos a gritos con colegas utilizando un lenguaje soez, desprenderse de su cinturón y exhibirlo amenazando con castigar a otros a cintarazos, y el arrojar botellas de agua a quienes criticaba. Sus acciones provocaron una inusitada aprobación pública puesto que indudablemente capitalizaban el hastío ciudadano con y su rechazo a la "clase política".

El episodio que colmó el vaso, sin embargo, fue su violenta incursión en una comisaría del Alto Paraná achacando a su Comisario haber dejado pasar el control policial a un camión cargado de contrabando y propinándole golpes en la cabeza al mismo y otros subordinados. El Senado decidió declarar la pérdida de su investidura y por tanto su expulsión. La estrella de Cubas se disipó de la misma manera súbita como comenzó cuando inició una campaña de crítica a la corrupción en el Alto Paraná, desafiando a los jueces que lo procesaban por disturbios con acciones como defecar en sus despachos. Estos hechos le granjearon simpatía y le permitieron ser electo Senador y hechos semejantes le causaron su remoción.

En la Cámara de Diputados se produjeron también hechos similares de graves acusaciones en contra de algunos de sus miembros, pero el espíritu corporativo primó y los mismos fueron protegidos. La excepción fue el caso del diputado Tomás Rivas, quien fue desaforado para enfrentar un proceso judicial (Última Hora 2019m).

Detrás de estos acontecimientos, especialmente en el Senado, subyacen dos elementos de gran importancia. Por un lado, se observa nítidamente el creciente poder de la indignación ciudadana que a través principalmente de las redes sociales ha logrado influenciar de manera decisiva el discurrir político. Por otra parte, puede verse también un elemento preocupante. Si las Cámaras del Congreso tienen el poder de expulsar a algunos de sus miembros electos por la simple mayoría absoluta de sus miembros ¿cómo podría esto afectar en el futuro a miembros embarcados en una crítica a los poderes hegemónicos y que podrían arbitrariamente ser expulsados por ello mismo?

Téngase en cuenta que la figura del fuero parlamentario tiene por objetivo proteger el ejercicio de la función legislativa y evitar la presión contra los congresistas. No se trata solamente de garantizar la libertad de opinión y expresión frente a acusaciones de libelos de difamación y calumnia, sino también de la

La influencia de la movilización ciudadana ha crecido en los últimos años. Ver por ejemplo: Duarte (2013), Duarte y González (2016); Herrera Fois (2017); Carrizosa (2018); Lopez (2019). 
posible utilización artera de causas supuestamente civiles, penales o comerciales para ejercer dicha presión de manera más sutil pero igualmente efectiva. ${ }^{9}$

Este riesgo no puede ser eliminado porque la Constitución, por lo que parecería ser un error, no contempla la mayoría calificada como un requerimiento para la pérdida de investidura. El artículo 201 establece las causas, pero no la mayoría requerida para su aplicación y el artículo 185 dispone que cuando la Constitución no instituye una mayoría calificada, la mayoría simple es suficiente. Hipotéticamente ello significa que, en una sesión con el quorum mínimo, 23 senadores, 12 senadores, o $27 \%$ de sus miembros pueden expulsar a un colega. Es decir que en una maniobra parlamentaria 22 senadores podrían dejar de concurrir a una sesión para no asumir un compromiso público y permitir que 12 miembros decreten la expulsión de un Senador. Así, sería más gravoso rechazar un veto que expulsar a un miembro del cuerpo.

\section{Golpe a la disciplina partidaria y la gobernabilidad}

En abril de 2019 se inició una apresurada discusión del sistema electoral de las listas sábanas, es decir cerradas y bloqueadas, tema que en realidad venía siendo planteado desde mucho tiempo atrás por diferentes sectores. El partido de derecha Patria Querida presentó un proyecto de desbloqueo que, bajo la presión mediática, pero también ciudadana, terminó incluido en la agenda del Senado.

En realidad, la propuesta del desbloqueo de las listas había sido ya presentado en el año 2001 y había sido objeto de una campaña de un grupo ciudadano que casualmente, con posterioridad, se convirtió en el Movimiento primero y partido después, Patria Querida.

La nueva ley establece un sistema de lista completa, cerrada y desbloqueada. En este sistema el elector vota por un candidato de su preferencia de cualquier lista. Luego de calculados los escaños que le corresponden a dicha fuerza política - cálculo hecho sobre la base de los votos recibidos por todos los candidatos de dicha lista - las bancas se asignan en orden descendente de preferencia, es decir en función a los votos obtenidos por cada candidato y, si restasen bancas a asignar, siguiendo el orden de la lista. ${ }^{10}$

Este proyecto de modificación fue aprobado sobre tablas y con modificaciones de fondo, es decir sin tan siquiera remitir para su estudio a las comisiones. El objetivo de la modificación fue incentivar el voto a la persona, no a la lista "sábana", empoderando así a los electores y des-empoderando a los partidos. La

Este peligro se ve acentuado porque la Fiscalía General de la República se ha convertido en un apéndice de poderosos intereses político-económicos. 
literatura sobre el tema en general es abundante, por ejemplo y especialmente Taagapera y Shugart (1989) y Shugart y Taagapera (2017). Debido a las características del sistema electoral paraguayo, sin embargo, la modificación no logrará su fin y generará en cambio graves y deletéreas consecuencias.

De particular relevancia para apreciar el impacto limitado en este caso es el trabajo de Carey y Shugart (1995) que elabora una fórmula de rank-ordering (1995: 425, 431) para clasificar las fórmulas electorales en función a su impacto sobre el voto reputacional, es decir el voto al candidato. El valor mínimo es 1 y el máximo 13. La fórmula adoptada en Paraguay, doble voto simultáneo, se ubica en la posición 9, es decir su efecto en dicho sentido será marginal. Si a dicho ranking basado en tres variables (sistema de selección de candidaturas, método de sumatoria de votos y número de votos asignado a cada elector) se agrega la cuarta, magnitud de los distritos, el resultado es aún peor pues lejos de fortalecer el poder ciudadano aumenta la fragmentación institucional, agrava el ya difícil dilema de acción colectiva de los partidos y por tanto empeora la calidad de la democracia.

Sin tener ninguna de las posibles ventajas del voto a la persona, el sistema tiene todas las desventajas del sistema de voto preferencial. Como es sabido (Tuesta Soldevilla 2013), este sistema producirá cinco consecuencias deletéreas. Primero, permitirá que con pocos votos preferenciales ciertos candidatos alteren sustancialmente el orden de la lista, simplemente porque los otros candidatos no tienen los recursos o la infraestructura electoral para lograr el mismo objetivo.

Segundo, llevará a que cada candidato haga su propia campaña, compitiendo contra sus supuestos compañeros de partido. Esto producirá una competencia de todos contra todos, agravará el dilema de acción colectiva de los partidos, y perjudicará especialmente los partidos pequeños.

Tercero, y concomitantemente, debilitará aún más a los partidos, ya severamente fragmentados y con serios problemas de gobernabilidad internos, pero también de apoyo u oposición a los gobiernos de turno. Su perfil se diluirá en un caleidoscopio de fracciones e individualidades. Cualquier intento de construir o incluso de percibir actores colectivos se ahogará en un individualismo reduccionista

Cuarto, aumentará los problemas de gobernabilidad del Ejecutivo en su relación con el Congreso puesto que le obligará a negociar individualmente con congresistas de muy distintas procedencias, preferencias ideológicas, intereses materiales, y aspiraciones políticas. Esto representará un mayor incentivo para la corrupción, la compraventa de votos, y el tráfico de influencia. Este punto has sido señalado recientemente en el Índice de Capacidad para Combatir la Corrupción de AS/COA (2020) como una de las razones por las cuales Paraguay se ubica en el puesto 12 de los 15 países incluidos, solo superado en debilidad por la República Dominicana, Bolivia y Venezuela (ABC Color 2020a).

Finalmente, agravará el problema del control del financiamiento de las campañas. ¿Quién financiará a los candidatos? ¿Qué rol jugará el narcotráfico denunciado como ya presente en el caso de numerosos diputados? ¿Y qué rol tendrán 
los sectores empresariales, especialmente la oligarquía sojera y ganadera? Coincidentemente, los medios que representan los principales grupos económicos del país se embarcaron en una fuerte campaña de apoyo a esta propuesta.

Finalmente, como cada candidato deberá presentar individualmente una rendición de cuentas al Tribunal Superior de Justicia Electoral a los efectos de determinar el subsidio estatal correspondiente, éste podía tener que controlar hasta 1,350 declaraciones distintas si se utilizara como parámetro las 30 listas de senadores que compitieron en 2018, y esto solamente para las listas a Senadores. En el caso de los candidatos a Diputados podría tratarse de otras 1,600, además de las de las candidaturas a las 19 gobernaciones y Juntas Departamentales.

A fin de resolver la dificultad de conteo de los votos, el Congreso aprobó, también sobre tablas, el uso de urnas electrónicas. El grave riesgo que las mismas ofrecen debido a la posibilidad de hackeo fue obviado. El Tribunal Superior de Justicia Electoral rápidamente convocó a una licitación para la adjudicación del servicio, alquilado, y otorgó el contrato a la que fue presentada como la única oferta aceptable. Al tratarse de un alquiler, no de una compra, esto permitirá subsecuentes licitaciones de renovación que podrán ser adjudicadas siguiendo los mismos parámetros (ABC Color 2020b).

Como resultado, la fragmentación de los partidos será aún mayor, la disciplina virtualmente inexistente y la gobernabilidad todavía más difícil, todo lo cual puede desembocar en la peruanización de la política paraguaya. Los principales beneficiarios serán los sectores del crimen organizado y los grandes conglomerados empresariales (para una visión mas amplia de la problemática de los sistemas electorales de América Latina, ver Tuesta Soldevilla 2013; Freidenberg y Uribe Mendoza 2019).

\section{División de la oposición}

A lo largo del año se observó también una aceleración del proceso de fragmentación partidaria. El sistema de partidos ya no es bipartidista en sentido estricto. Si bien en el campo electoral, los partidos colorado y liberal capturan aproximadamente dos tercios de los votos, en la arena política la realidad es mucho más compleja.

El año 2019 demostró de manera particularmente clara que todos los actores políticos dependen de otros para lograr sus objetivos. Como viene sucediendo desde el gobierno de Juan Carlos Wasmosy (1993-1998), la fragmentación política se ha convertido en la constante institucional (Martínez-Escobar 2015).

El bipartidismo es hoy en realidad un sistema de al menos cuatro partidos, pues la ANR (Asociación Nacional Republicana-Partido Colorado) tanto como el PLRA (Partido Liberal Radical Auténtico) se encuentran divididos en varias facciones. Y además están las terceras y cuartas fuerzas. Hasta 2003 el tercer 
partido fue el Encuentro Nacional, desde el 2003 hasta el 2008 el partido Patria Querida, que lo desplazó del escenario político, y desde 2008 en adelante su sumó el Frente Guasu y otros partidos menores (Martínez-Escobar 2015).

La representación política en la Cámara de Senadores, la cámara nacional, evidencia esta realidad. La tabla 2 es una estimación del nivel de fragmentación de la Cámara de Senadores. Los números del autor son aproximados porque las lealtades fueron cambiando a lo largo del período.

Tabla 2. Estimación de la fragmentación partidaria en la Cámara de Senadores (1993-2018)

\begin{tabular}{lcccccc}
\hline Periodo & 1993 & 1998 & 2003 & 2008 & 2013 & 2018 \\
Partido & 1998 & 2003 & 2008 & 2013 & 2018 & 2023 \\
\hline ANR 1 & 4 & 15 & 9 & 11 & 8 & $8+3$ \\
ANR 2 & 15 & 9 & 7 & 4 & 10 & $5+1$ \\
PLRA 1 & 14 & 8 & 7 & 6 & 7 & 8 \\
PLRA 2 & 3 & 4 & 5 & 8 & 6 & 6 \\
Encuentro & 9 & 8 & 1 & - & 1 & - \\
Nacional & & & & & & \\
Patria & & & 7 & 4 & - & 3 \\
Querida & & & & & & \\
Frente & & & & 1 & 3 & 7 \\
Guasu & & & 9 & 9 & 5 & 2 \\
PDP & & & & & & \\
UNACE y otros & & & & & & \\
\hline
\end{tabular}

Los datos en la Tabla 2 demuestran que en realidad hay dos Partidos Colorado y dos PLRA, aunque el clivaje haya cambiado con el tiempo y en las coyunturas electorales se unifiquen. Por eso cuando se afirma que el éxito del Partido Colorado es ser a la vez oficialismo y oposición, hay que extender esta afirmación al PLRA.

En el caso del Partido Colorado esta diferencia le fortalece porque siempre la candidatura para el siguiente periodo presidencial puede descargar el débito en el gobierno saliente y presentarse no como continuidad sino como cambio. Así lo ha hecho el gobierno de Cubas Grau con respecto al de Wasmosy, el de Duarte Frutos con respecto al de González Macchi y el de Abdo Benítez con respecto al de Cartes.

En el PLRA sin embargo la situación es distinta. La persistencia de un ala partidaria, en este caso el llanismo, que pacta constantemente, casi como vocación, con el Partido Colorado debilita su capacidad de liderar la oposición. Esta tendencia, acentuada desde 2013, le ha hecho perder al partido su credibilidad como alternativa de poder y lo ha convertido en un eterno junior partner del 
gobierno de turno. Consecuentemente, al momento de las elecciones no es percibido como alternativa real de poder. Resta por ver, sin embargo, si la fuerte impronta alternativa que le ha impreso su actual presidente Efraín Alegre en las elecciones de 2013 y 2018, logra el resultado deseado en 2023.

\section{LA RECESIÓN ECONOMICA}

En el primer semestre del año 2019 la economía paraguaya entró en recesión (5 Días 2019). La caída del PIB fue del 3\% y fue producto de la crisis de los países vecinos y principales socios comerciales, y de condiciones climáticas severamente adversas (Banco Mundial 2020). Este resultado no se observaba desde la caída de 2009 cuando el país fue arrastrado por la crisis global de la Bolsa de Valores de 2008 y la gran recesión que produjo.

Sin embargo, la recuperación económica del segundo semestre del año, especialmente del último trimestre logró amortiguar el golpe y produjo para el año un crecimiento de $0 \%$ con la expectativa de un crecimiento de efecto rebote en 2020 de $4.1 \%$ (Figura 2) (5 Días 2020). Obviamente, como resultado de la pandemia del COVID-19 la expectativa para 2020 es ahora de una recesión del orden del $3.5 \%$ (Hernaiz y Feal 2020) relativamente moderada en términos comparativos debido al buen clima, al gran peso del sector agropecuario y al impacto mundial más reducido sobre las exportaciones de granos y carne.

Figura 2. Tasa de crecimiento del PBI paraguayo.

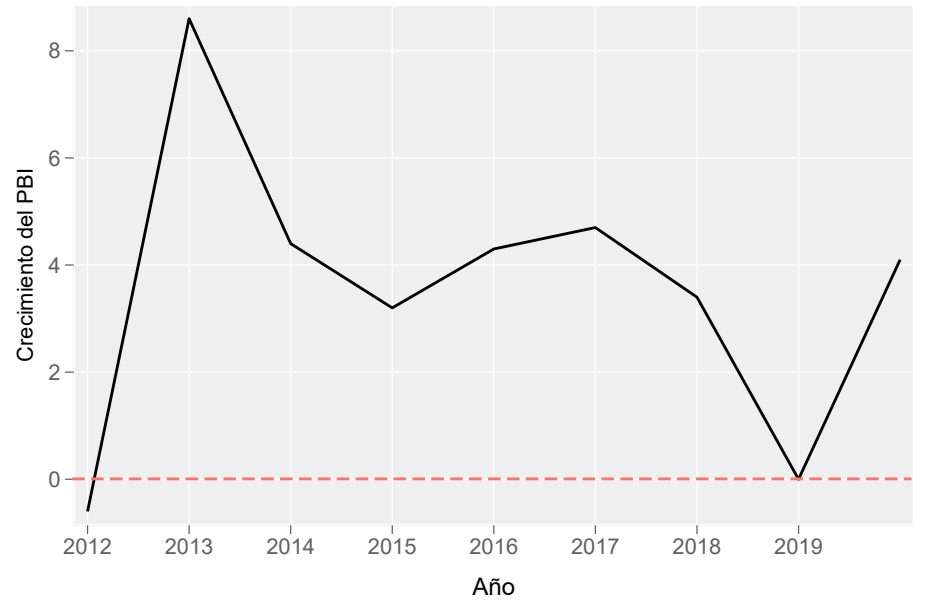

Fuente: Banco Central del Paraguay

A efectos comparativos es útil recurrir también al informe "La Economía Paraguaya de los últimos 20 años" publicado por la organización DENDE (Desa- 
rrollo en Democracia), que permite seguir la evolución de la economía en un periodo más largo, el período 1995-2015 (DENDE 2016).

Figura 3. Tasa de crecimiento del PBI paraguayo en veinte años.

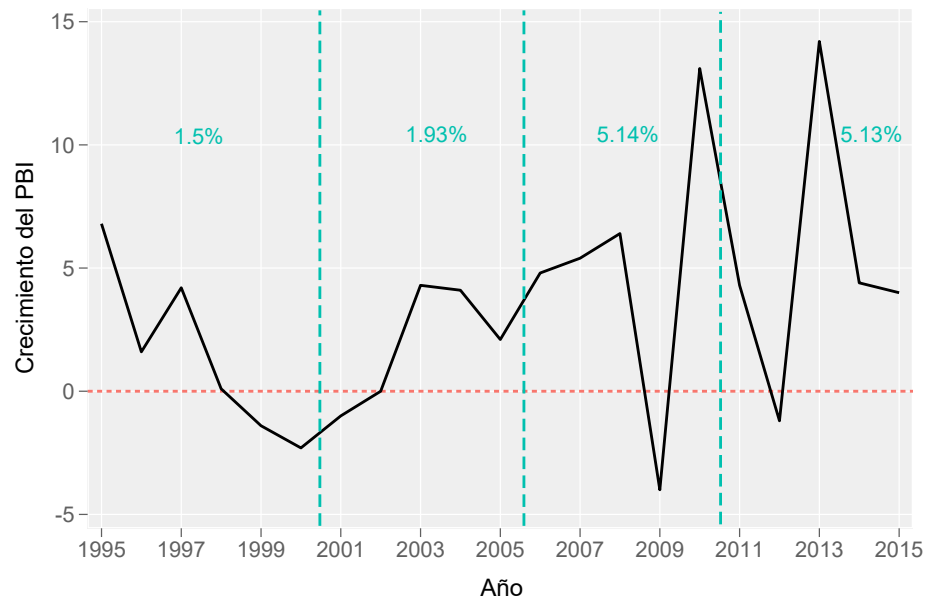

Fuente: DENDE.

La pobre performance económica del año 2019 impactó severamente sobre los niveles de pobreza, desempleo, déficit fiscal y deuda externa. En el caso de la tasa de pobreza que venía disminuyendo sostenidamente desde hace casi veinte años, el ritmo se desaceleró produciendo un virtual estancamiento en torno al $24 \%$ a nivel nacional, $34 \%$ a nivel rural y $18 \%$ a nivel urbano.

Otros dos impactos importantes fueron el aumento del déficit fiscal y la deuda externa, ambos con posibles serias repercusiones en el futuro. El déficit fiscal se encontraba controlado desde la reforma tributaria de 2004. En 2013 se aprobó la Ley de Responsabilidad Fiscal, que establecía un tope de endeudamiento de 1.5\% del PIB. En realidad, este tope era más que nada un freno a la tendencia del Congreso a aumentar el gasto público más allá de lo posible y prudente y de aprobar sistemáticamente presupuestos deficitarios. Esta constante obligaba al Poder Ejecutivo a contener el déficit fiscal - que técnicamente no existía pues el Congreso simplemente aumentaba la estimación de ingresos para mostrar un equilibrio nominal y ficticio - por la vía de un decreto reglamentario de la Ley de Presupuesto y el ritmo de ejecución mensual. El efecto era sin embargo que como no se podían controlar los gastos rígidos, sueldos, salarios y pensiones, el peso del ajuste recaía principalmente sobre la inversión.

La Ley de Responsabilidad Fiscal, sin embargo, no contemplaba la eventual necesidad de adoptar medidas contra cíclicas. Debido a la recesión de 2019, el Poder Ejecutivo remitió un proyecto de modificación de la Ley que le permitió 
eludir el tope y a fines de año el déficit se ubicó en 3 \% de PIB (5 Días 2019). Para 2020 se estima un déficit más cercano al 5\%. Si bien es cierto que estas medidas son contra cíclicas, es decir temporales, es igualmente cierto que será muy difícil para futuros gobiernos volver a poner el déficit bajo control habida cuenta la tendencia del Congreso a aumentar el gasto y la debilidad del Ejecutivo vis-ávis el Congreso en materia presupuestaria. Como se pudo ver en la sección que analiza los vetos, el Ejecutivo vetó parte de la Ley de Presupuesto de 2019 y el Congreso rechazó el veto. El veto se dirigía a controlar el aumento discrecional del gasto salarial aprobado por el Congreso que llegó al punto de segmentar finamente y hasta personalizar los aumentos salariales. Esto es debido a que el Congreso aprueba no solo el Presupuesto sino también el Anexo de Personal, es decir el listado de cargos y salarios. La Figura 4 ilustra la evolución del déficit fiscal en la última década.

Figura 4. Déficit fiscal (2009-2019)

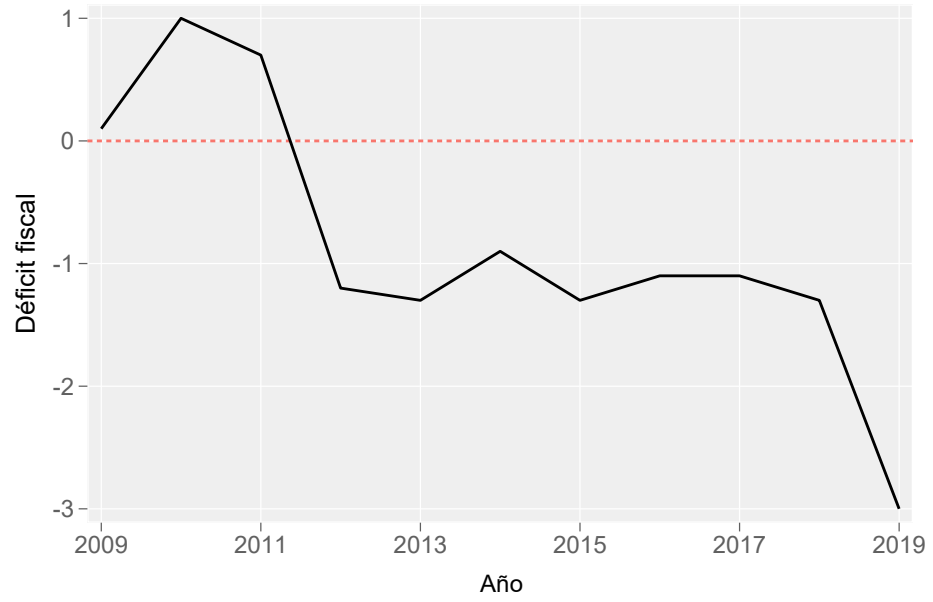

Fuente: datos del Ministerio de Hacienda.

Otro impacto de importancia y repercusión ha sido el del peligroso aumento de la deuda externa, especialmente la contraída a través de la colocación de bonos. La deuda pública total aumentó $10.2 \%$ en 2019 con respecto a 2018 y pasó de representar 10.8\% del PIB en 2013 a 23\% en 2019. Desde 2012 el gobierno ha recurrido a colocar bonos en la Bolsa de New York. A diferencia de los préstamos de los organismos multilaterales que se contraen para proyectos específicos y se desembolsan en función a un cronograma de ejecución, la colocación de bonos le permite al gobierno generar importantes recursos que pueden utilizarse discrecionalmente y sin control sobre su ejecución.

Desde la primera colocación de bonos por 500 millones de dólares en 2013, se ha mantenido la tendencia. Aún más peligroso es que una parte importante 
de dichos recursos, 36\% ha sido utilizado para pagar la deuda anterior. En la última colocación de 2019 por 500 millones de dólares 40 \% fue para amortizar deuda anterior (Ministerio de Hacienda 2020). Mientras hay quienes argumentan que se trata de un re-perfilamiento de la deuda, lo cierto es que siempre se busca eludir el costo presente y aumentar el costo futuro, cargando así con una onerosa hipoteca a gobiernos y generaciones del porvenir. En la figura 5 se observa la evolución del endeudamiento externo vía bonos soberanos.

Figura 5. Colocación de bonos soberanos

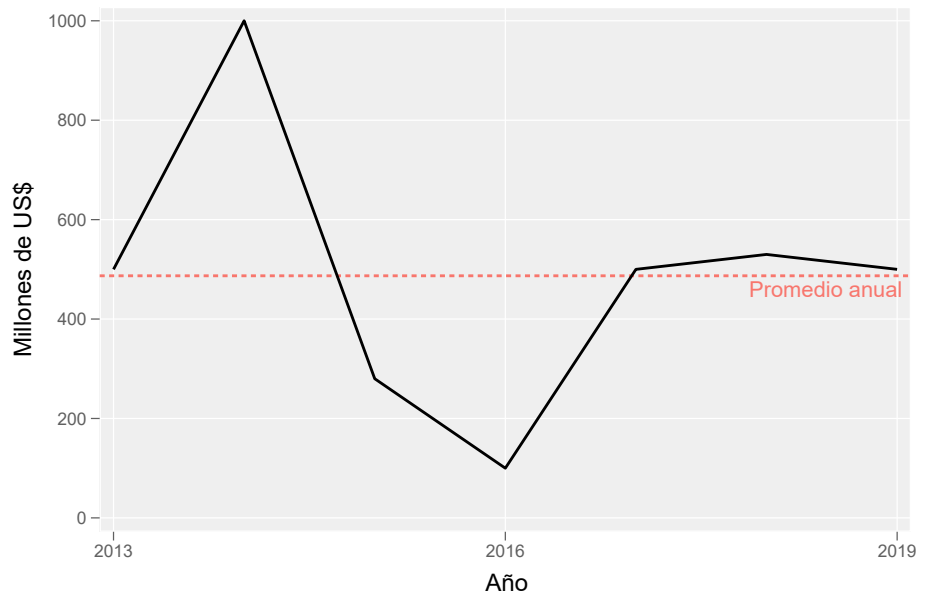

Fuente: Ministerio de Hacienda

Las perspectivas son aún más sombrías para 2020, puesto que se espera una colocación de bonos por cerca de 2,000 millones de dólares, con lo cual la deuda externa rozaría el 30\% del PIB considerado como el máximo de endeudamiento recomendable.

\section{CONCLUSION}

Annus horribilis. En esos términos se caracterizaba al primer año de gobierno del presidente Mario Abdo Benítez al inicio de este artículo. Podría parecer quizás un juicio demasiado duro o estricto. Como el lector podrá apreciar, sin embargo, del conjunto de las variables analizadas no es posible extraer otra conclusión.

En las tres dimensiones analizadas en detalle -política exterior, política doméstica y economía- el gobierno ha tenido que sortear innúmeros reveses, muchos de ellos producto de su propia acción, o inacción. La calidad de la democracia sigue erosionándose y su futuro está en riesgo, no porque se pueda regresar a 
un régimen autoritario sino porque de llegar a niveles tan bajos de efectividad en la gestión y de alienación en la representación, abre las puertas de par en par a experimentos mesiánicos o proyectos iliberales que conservan el proceso eleccionario pero desnaturalizan todos los elementos centrales de una democracia representativa y clausuran o cooptan los canales de participación ciudadana (Zakaria 1997).

En el terreno de la oposición, es observable una incipiente unidad de los partidos políticos de oposición. No se puede aún vaticinar si esta convergencia llegará a 2023 convertida en alianza electoral. De una u otra manera, es posible que en el año 2020 se resuelvan muchos de los interrogantes decisivos para la elección de 2023.

\section{REFERENCIAS}

5 Días. 2019, 12 de noviembre. "Hacienda justifica aumento del déficit fiscal." Recuperado el 31 de julio de 2020 de https:/ / www.5dias.com.py/2019/11/hacienda-justifica-aumento-del-deficit-fiscal/

5 Días. 2020, 17 de febrero. "El 2019 cerró con estancamiento económico." Recuperado el 31 de julio de 2020 de https://www.5dias.com.py/2020/02/el-2019-cerro-con-estancamiento-economico/

ABC Color. 2018, 23 de marzo. “En Itaipú, en 31 años, el Paraguay regaló US\$ 54.000 millones en energía." Recuperado el 31 de julio de 2020 de https://www.abc.com.py/ edicion-impresa/economia/en-itaipu-en-31-anos-el-paraguay-regalo-us-54000-millones-en-energia-1686462.html

ABC Color. 2019a, 6 de agosto. "Los reveladores mensajes alrededor del acuerdo secreto." Recuperado el 31 de julio de 2020 de https://www.abc.com.py/nacionales/2019/08/06/los-reveladores-mensajes-alrededor-del-acuerdo-secreto/

ABC Color. 2019b, 17 de abril. "La primera visita de un secretario de Estado y su relevancia." Recuperado el 31 de julio de 2020 de https: / / www.abc.com.py/nacionales/la-primera-visita-de-un-jefe-de-estado-y-su-relevancia-1802087.html

ABC Color. 2019c, 4 de Julio. "Corte-IDH rechaza demanda de Arrom." Recuperado el 31 de julio de 2020 de https://www.abc.com.py/nacionales/arrom-y-marti-cidh-fallaa-favor-de-paraguay-1820640.html

ABC Color. 2019d, 28 de noviembre. "Expulsan a "Payo" Cubas del Senado." Recuperado el 31 de julio de 2020 de https://www.abc.com.py/nacionales/2019/11/28/expulsan-a-paraguayo-cubas-del-senado/

ABC Color. 2020a, 8 de junio. "Paraguay, entre los peores para combatir la corrupción." Recuperado el 31 de julio de 2020 de https:/ /www.abc.com.py/nacionales/2020/06/08/ paraguay-entre-los-peores-para-combatir-la-corrupcion/

ABC Color. 2020b, 21 de febrero. "Urnas electrónicas para ensayos llegan la próxima semana." Recuperado el 31 de julio de 2020 de https://www.abc.com.py/nacionales/2020/02/21/urnas-electronicas-para-ensayos-llegan-la-proxima-semana/

AFP. 2019, 21 de agosto. "EE.UU. elogia a Paraguay por declarar terrorista a Hezbollah y Hamas." ABC. Recuperado el 31 de julio de 2020 de https://www.abc.com.py/internacionales /2019/08/21/eeuu-elogia-a-paraguay-por-declarar-terrorista-a-hezbollah-y-hamas/

Agencia EFE. 2019, 30 de julio. "El pacto con Brasil tumba al canciller en la primera crisis del presidente paraguayo." Recuperado el 31 de julio de 2020 de https://www.efe. $\mathrm{com} /$ efe/america/politica/el-pacto-con-brasil-tumba-al-canciller-en-la-primera-crisis-del-presidente-paraguayo/20000035-4033007 
AP. 2018, 7 de septiembre. “Paraguay Urges Israel to Reconsider 'Exaggerated' Embassy Closure." Haaretz. Recuperado el 31 de julio de 2020 de https://www.haaretz. com/israel-news/paraguay-urges-israel-to-reconsider-exaggerated-embassy-closure-1.6463242

AS/COA (America Society/Council of Americas). 2020. The Capacity to Combat Corruption Index. New York. Recuperado el 31 de julio de 2020 de https:/ / www.as-coa.org/articles/2020-capacity-combat-corruption-index

Banco Mundial. 2020, 20 de abril. "Paraguay: panorama general." Recuperado el 31 de julio de 2020 de https://www.bancomundial.org/es/country/paraguay/overview

Cálcena Ramírez, Juan. 2019, 16 de diciembre. “Del pacto secreto en Itaipú al juicio político: entreguistas, antipatriotas y un frágil gobierno." $A B C$. Recuperado el 31 de julio de 2020 de https://www.abc.com.py/especiales/anuario-2019/2019/12/16/del-pacto-secreto-en-itaipu-al-juicio-politico-entreguistas-antipatriotas-y-un-fragil-gobierno/

Carey, John y Matthew Shugart, 1995. "Incentives to Cultivate a Personal Vote: a Rank Ordering of Electoral Formulas." Electoral Studies 14(4): 417-439.

Carrizosa, Andrés. 2018. "Paraguay 2017: competencia política en las Cámaras, en las calles y en las urnas." Revista de Ciencia Política 37(2): 543-562.

Carter, Miguel. 2019. "Itaipú, Causa Nacional. La Riqueza Energética Perdida del Paraguay: De cara la revisión de 2023." Conferencia dictada el 8 de Abril de 2019 en el Teatro de las Américas del Centro Cultural Paraguayo-Americano.

DENDE. 2016. “La economía paraguaya en los últimos 20 años." Recuperado el 31 de julio de 2020 de https://www2.deloitte.com/py/es/pages/about-deloitte/articles/la-economia-paraguaya-en-los-ultimos-20-anos.html

Duarte Recalde, Liliana. 2013. "Paraguay: interrupción al proceso de consolidación de la democracia." Revista de Ciencia Política 33(1): 303-324.

Duarte Recalde, Liliana y Cynthia González Ríos. 2016. “Paraguay: Entre las movilizaciones sociales y el reordenamiento electoral." Revista de Ciencia Política 36(1): 287-312.

Freidenberg, Flavia y Cristhian Uribe Mendoza. 2019. "Las reformas político-electorales en América Latina (2015-2018)." Revista de Estudios Políticos 0(185): 191-223.

González Bozzolasco, Ignacio. 2017. "Paraguay: la reelección presidencial y los inicios de la carrera electoral 2018." Revista de Ciencia Política 37(2): 543-562.

Hernaiz, Daniel y Soledad Feal. 2020, 3 de abril. "El impacto del Covid-19 en las economías de la región Cono Sur: Paraguay." Publicaciones BID. Recuperado el 31 de julio de 2020 de https://publications.iadb.org/publications/spanish/document/El_impacto_del_COVID-19_en_las_econom\%C3\%ADas_de_la_regi\%C3\%B3n_Cono_Sur.pdf

Herrera Fois, Montserrat. 2017. "La contienda política en la Universidad Nacional de Asunción (UNA en el periodo 1980-2015. Un análisis desde la Teoría de los Procesos Políticos." Tesis para optar por el título de licenciada en ciencia política. Asunción: UCA.

La Nación. 2019, 9 de marzo. "Abdo encabezará renegociación del Anexo C del Tratado de Itaipú." Recuperado el 31 de julio de 2020 de https://www.lanacion.com.py/ politica_edicion_impresa/2019/03/09/abdo-encabezara-renegociacion-del-anexo-c-del-tratado-de-itaipu/

López, Magdalena. 2019. "Paraguay en un año electoral (2018): trayectorias económicas, políticas y sociales en la transición entre el gobierno colorado saliente y el entrante." Revista de Ciencia Política 39(2): 313-340.

Lovera, Nora. 2019, 13 de mayo. "Senadores resolvieron pérdida de investidura del colega Víctor Bogado." Senado Paraguay. Recuperado el 31 de julio de 2020 de http:/ /www. senado.gov.py/index.php/noticias/noticias-presidencia/2997-senadores-resolvieron-perdida-de-investidura-del-colega-victor-bogado-2019-05-13-16-50-31

Manning, Bayless. 1977. "The Congress, the Executive and Intermestic Affairs: Three Proposals." Foreign Affairs 55(2): 306-324.

Martínez-Escobar, Fernando. 2015. “El Sistema de Partidos del Paraguay a través de la distribución del poder y las reglas del juego 1989-2013." Revista Paraguaya de Sociología 52(147): 99-126. 
Maza, Cristina. 2018, 9 de junio. "Trump Administration pressures Paraguay to Move Embassy to Jerusalem." Newsweek. Recuperado el 31 de Julio de 2020 de https:// newsweek.com/trump-administration-pressures-paraguay-move-embassy-jerusalem-too- 1110070

Ministerio de Hacienda 2020. “Bonos soberanos, ¿en qué se invierten?" Recuperado el 31 de julio de 2020 de https://www.hacienda.gov.py/web-hacienda/archivo.php?a=f1f1f4fak6fek5ffk4bfk1k3f5k4f5fek5f1f3f9fffef5k4bfc2c0c1c9bfc2c0c1c9bdc0c2bdc0c5b0f2fffeffk4b0k4fff2f5k3f1k3feffk4bek1f4f6f1090\&x=d3d3072\&y=b9b9058

Shugart, Matthew y Rein Taagepera. 2017. "Votes From Seats. Logical Models of Electoral Systems." New York: Cambridge University Press.

Taagepera, Rein y Matthew Shugart. 1989. "Seats and Votes: The Effects of Determinants of Electoral Systems." New Haven: Yale University Press.

Tuesta Soldevilla, Fernando. 2013. “Un voto letal: el voto preferencial y los partidos políticos en el Perú." Politai: Revista de Ciencia Política 4(7): 107-118.

Turner, Brian. 2014. "Paraguay: la vuelta del partido colorado al poder." Revista de Ciencia Política 34(1): 249-266.

Última Hora. 2019a, 25 de agosto. "Mario Abdo es más rechazado que Cartes en su primer año de gestión." Recuperado el 31 de julio de 2020 de https: / /www.ultimahora.com/ mario-abdo-es-mas-rechazado-que-cartes-su-primer-ano-gestion-n2840073.html

Última Hora. 2019b, 3 de agosto. “Quién es Joselo Rodríguez? El abogado que pone en vilo a Hugo Velázquez." Recuperado el 31 de julio de 2020 de https://www.ultimahora.com/quien-es-joselo-rodriguez-el-abogado-que-pone-vilo-hugo-velazquez-n2835784.html

Última Hora. 2019c, 1 de agosto. "Juicio político: Embajador de EEUU celebra "prudencia" de líderes." Recuperado el 31 de julio de 2020 de https:/ / www.ultimahora.com/juicio-politico-embajador-eeuu-celebra-prudencia-lideres-n2835379.html

Última Hora. 2019d, 17 de agosto. “El 62,3\% cree que Marito no está preparado para negociar en Itaipú." Recuperado el 31 de julio de 2020 de https: / /www.ultimahora.com/ el-623-cree-que-marito-no-esta-preparado-negociar-itaipu-n2838543.html

Última Hora. 2019e, 6 de septiembre. "Mario Abdo se jacta de amistad con EEUU durante visita de Ivanka Trump." Recuperado el 31 de julio de 2020 de https://www.ultimahora.com/mario-abdo-se-jacta-amistad-eeuu-visita-ivanka-trump-n2842315.html

Última Hora. 2019f, 3 de enero. "El plagio que derivó en un segundo secuestro y tumbó a dos ministros." Recuperado el 31 de julio de 2020 de https: / www.ultimahora.com/ el-plagio-que-derivo-un-segundo-secuestro-y-tumbo-dos-ministros-n2789141.html

Última Hora. 2019g, 8 de octubre. "Arrom, Martí y Colmán, con refugio en Finlandia." Recuperado el 31 de julio de 2020 de https: / / www.ultimahora.com/arrom-marti-y-colman-refugio-finlandia-n2848237.html

Última Hora. 2019h, 11 de agosto. "Marito se rodea de asesores de poco peso por su falta de liderazgo." Recuperado el 31 de julio de 2020 de https:/ /www.ultimahora.com/ marito-se-rodea-asesores-poco-peso-su-falta-liderazgo-n2837273.html

Última Hora. 2019i, 30 de septiembre. "La mitad del Gabinete de Mario Abdo está en el ojo de la tormenta." Recuperado el 31 de julio de 2020 de https: / www.ultimahora.com / la-mitad-del-gabinete-mario-abdo-esta-el-ojo-la-tormenta-n2846582.html

Última Hora. 2019j, 4 de octubre. "Julio Ullón deja el Gabinete Civil tras cuestionamientos a su gestión." Recuperado el 31 de julio de 2020 de https:/ /www.ultimahora.com/ julio-ullon-deja-el-gabinete-civil-cuestionamientos-su-gestion-n2847474.html

Última Hora. 2019k, 13 de octubre. "Posible cambio en el Gobierno: ¿Euclides Acevedo al Ministerio del Interior?" Recuperado el 31 de julio de 2020 de https://www.ultimahora.com/posible-cambio-el-gobierno-euclides-acevedo-al-ministerio-del-interior-n2849054.html

Última Hora. 20191, 6 de junio. "Dionisio Amarilla es expulsado de la Cámara de Senadores." Recuperado el 31 de julio de 2020 de https:/ / www.ultimahora.com/dionisio-amarilla-es-expulsado-la-camara-senadores-n2824021.html 
Última Hora. 2019m, 22 de mayo. "Diputados retira los fueros al colorado Tomás Rivas." Recuperado el 31 de julio de 2020 de https:/ / www.ultimahora.com/diputados-retira-los-fueros-al-colorado-tomas-rivas-n2820848.html

Vale Columbia Center on Sustainable International Investment (VCC). 2013. "Leveraging Paraguay's Hydropower for Sustainable Economic Development". Final Report. Recuperado el 31 de julio de 2020 de http:/ / ccsi.columbia.edu/files/2013/11/Leveraging_Paraguays_Hydropower_for_Economic_Development.pdf

White House. 2019, 13 de diciembre. "Joint Statement from President Donald J. Trump and President Mario Abdo Benitez." Recuperado el 31 de Julio de 2020 de https: / /www.whitehouse.gov/briefings-statements/joint-statement-president-donald-j-trump-president-mario-abdo-benitez/

Zakaria, Fareed. 1997. "The Rise of Illiberal Democracy." Foreign Affairs 76(6): 22-43

Recibido: 11 de junio, 2020

Aceptado: 5 de agosto, 2020

Diego Abente Brun es director del programa de Estudios Latinoamericanos y Hemisfericos del Elliott School of International Affairs, The George Washington University. E-mail: dabente@gwu. edu 
